\title{
Prognostic Significance of HER-2 and p53 Expression in Gallbladder Carcinoma in North Indian Patients
}

\author{
Anjali Singh ${ }^{a}$ e Pramod K. Mishra $^{b}$ Sundeep Singh Salujab Majid A. Talikotic \\ Pawan Kirtani $^{\mathrm{d}}$ Abul Kalam Najmi ${ }^{\mathrm{e}}$ \\ ${ }^{a}$ Department of Pharmaceutical Medicine, Faculty of Pharmacy, Jamia Hamdard, ${ }^{b}$ Department of Gastro-Intestinal \\ Surgery, G.B. Pant Hospital, Delhi University, 'Department of Surgical Oncology, HAH Centenary Hospital,

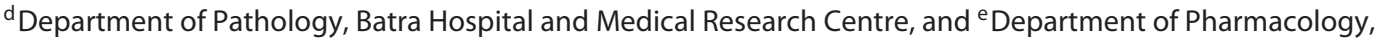 \\ Faculty of Pharmacy, Jamia Hamdard, New Delhi, India
}

\section{Key Words}

Gallbladder cancer · HER-2 · p53 - Immunohistochemistry ·

Survival plots

\begin{abstract}
Background/Objective: Proto-oncogenes (HER-2) and tumor suppressor genes (p53) are commonly deregulated in gallbladder cancer (GBC). Available literature discloses skewed data from endemic Asian countries, especially north India. This study evaluates the prognostic significance of HER-2 and p53 in GBC patients from two major hospitals. Methods: Sixty resectable tumor and control specimens were prospectively collected from December 2012 to January 2016. Immunohistochemical staining was done using monoclonal antibodies to semiquantitatively evaluate HER2 and p53 protein expression. The criterion for HER-2 positivity was set at $>30 \%$ tumor cells showing complete, membranous staining while p53 positivity was established at $<50 \%$ tumor cells showing complete nuclear staining. Clinicopathological correlations were drawn with major clinical outcomes. Results: It was observed that $36.67 \%$ (22/60) tumor
\end{abstract}

cases and 5\% (3/60) control cases showed strong HER-2 overexpression significantly correlating with sex, T-stage, nodal spread and distant metastasis ( $p<0.05$ ), while $33.3 \%$ $(20 / 60)$ positivity was observed for p53 in tumor cases and $1.7 \%(1 / 60)$ in control cases. Multivariate analysis showed HER-2 ( $p=0.04$; hazard ratio: 2.36 ; $95 \%$ confidence interval: 1.04-5.33) and p53 ( $p=0.03$; hazard ratio: 5.63 ; $95 \%$ confidence interval: 1.21-26.26) expression to be independent prognostic factors. Conclusion: Our study thus suggests the plausible role of HER-2 and p53 expression in worse prognosis of GBC in a north Indian population.

@ 2016 S. Karger AG, Basel

\section{Introduction}

Critical data from the Surveillance, Epidemiology, and End Results (SEER) program (1992-2000) show that the incidence of gallbladder cancer (GBC) is assessed at 2.5 per 100,000 persons making it the most common primary biliary tract malignancy, representing $46 \%$ of all such malignancies [1]. Major pockets of significantly high oc-

\section{KARGER}

E-Mail karger@karger.com www.karger.com/ocl
(C) 2016 S. Karger AG, Basel

0030-2414/16/0916-0354\$39.50/0
Dr. Abul Kalam Najmi

Department of Pharmacology, Faculty of Pharmacy Jamia Hamdard

New Delhi 110062 (India)

E-Mail aknajmi@hotmail.com 
currences include Central and South America (Chile, Mexico, and Bolivia), Central and Eastern Europe (Hungary, Poland, Czechoslovakia, and Austria) and Japan [2]. The Indian Council of Medical Research (ICMR)-WHO project on the development of a cancer atlas in India has reflected that the occurrence of GBC is predominantly higher in northern India [3]. Recent literature from the reports of the National Cancer Registry Programme of the ICMR suggests that the incidence of GBC corresponds to 3.6 per million in males and 7.4 per million in females in Delhi, India, as compared to 1.13 per million in the US $[4,5]$. Women represent almost three fourths of GBC victims and their highest incidence rate globally occurs in Delhi, yet only few common and specific gene studies are available from this high-propensity region $[6,7]$. GBC has also been reported to show a variable expression pattern among different ethnic groups.

GBC results via the dysplasia-metaplasia sequence (major pathway) and involves multiple cascades of ERBB and PI3K-AKT signaling among others [8]. The 5-year survival rate for $\mathrm{GBC}$ is $32 \%$ and for the advanced stage it is only $10 \%$ [9]. Current studies have focused on the importance of oncogenes (EGFR, HER-2, K-ras), tumor suppressor genes (p53, FHIT), cell cycle regulators (cyclin $\mathrm{D}$, cyclin $\mathrm{E}$ ), and micro-RNAs in the development and prognosis of GBC [10]. HER-2 expression evaluation as a biomarker for non-breast cancers has been gaining importance [11]. Among the array of responsible genes, one of the most flagrant genetic aberrations was ascribed to HER-2 in GBC [10]. Yan et al. [12] reported that HER2 overexpression was detected predominantly in malignancies of epithelial origin. Furthermore, the availability of FDA-approved agents targeting HER-2-positive malignancies, such as trastuzumab and pertuzumab (humanized monoclonal antibodies) and lapatinib and afatinib (dual EGFR/HER2 inhibitors), makes it a marker of choice for testing in GBC.

The PI3K/Akt/mTOR pathway has been closely linked to the pathogenesis of numerous carcinogenic conditions. Deregulation of PI3K signaling as a consequence of PIK3CA mutations or PTEN loss has been described in 5-12 and 50\% of human GBC, respectively [13]. Genotoxic as well as nongenotoxic inflictions to the cells give rise to the activation of the $\mathrm{p} 53$ gene, which acts as a gatekeeper gene to watch cell proliferation against cancer. Mutated p53 proteins have a longer half-life as compared to their wild-type counterparts and can be easily assessed by standard immunohistochemistry methods.

However, concrete results have not been obtained due to a limited number of resectable GBC cases presented at
Table 1. Population characteristics

\begin{tabular}{|c|c|c|}
\hline Factor & Category & $\begin{array}{l}\text { Population } \\
\text { fraction } \\
(\mathrm{n}=60)(\%)\end{array}$ \\
\hline Age & $\begin{array}{l}<50 \text { years old } \\
>50 \text { years old }\end{array}$ & $\begin{array}{l}15(31.25) \\
33(68.75)\end{array}$ \\
\hline Gender & $\begin{array}{l}\text { Male } \\
\text { Female }\end{array}$ & $\begin{array}{l}15(25) \\
45(75)\end{array}$ \\
\hline Presence of stones & $\begin{array}{l}\text { Negative } \\
\text { Positive }\end{array}$ & $\begin{array}{l}20(33.33) \\
40(66.67)\end{array}$ \\
\hline Macroscopic type & $\begin{array}{l}\text { Mass forming } \\
\text { Non-mass forming }\end{array}$ & $\begin{array}{l}24(40) \\
36(60)\end{array}$ \\
\hline $\begin{array}{l}\text { Lymph node metastasis } \\
(\mathrm{N})\end{array}$ & $\begin{array}{l}\text { Negative } \\
\text { Positive }\end{array}$ & $\begin{array}{l}43(71.67) \\
17(28.33)\end{array}$ \\
\hline Pathological grade $(\mathrm{T})$ & $\begin{array}{l}1+2 \\
3+4\end{array}$ & $\begin{array}{l}27(45) \\
33(55)\end{array}$ \\
\hline Distant metastasis (M) & $\begin{array}{l}\text { Absent } \\
\text { Present }\end{array}$ & $\begin{array}{l}46(76.67) \\
14(23.33)\end{array}$ \\
\hline $\begin{array}{l}\text { Histological } \\
\text { classification }\end{array}$ & $\begin{array}{l}\text { Well-differentiated } \\
\text { Moderately differentiated } \\
\text { Poorly differentiated }\end{array}$ & $\begin{array}{l}17(28.33) \\
25(41.67) \\
18(30)\end{array}$ \\
\hline $\begin{array}{l}\text { Lymphovascular } \\
\text { invasion }\end{array}$ & $\begin{array}{l}\text { Negative } \\
\text { Positive }\end{array}$ & $\begin{array}{l}34(56.67) \\
26(43.33)\end{array}$ \\
\hline Perineural invasion & $\begin{array}{l}\text { Negative } \\
\text { Positive }\end{array}$ & $\begin{array}{l}36(60) \\
24(40)\end{array}$ \\
\hline
\end{tabular}

the hospital. We, therefore, attempt to evaluate the immunoexpression of HER-2 and p53 receptors in 60 resectable prospective GBC cases across two major hospitals based in Delhi, India, and determine their prognostic value in the selected GBC cohort.

\section{Methods}

Tissue Specimens

Sixty freshly resected GBC cases were collected from the G.B. Pant hospital (associated with Maulana Azad Medical College), and $\mathrm{HAH}$ centenary hospital from Delhi, India, after obtaining ethical clearance from both the hospitals and informed consent from patients. As control, noncancerous adjacent tissues from each patient were collected routinely from the surgery department of the participating hospitals. Also, a structured questionnaire was prepared to obtain information on demographic, clini$\mathrm{cal}$, and epidemiological factors. None of the patients had received any radio- or chemotherapy before surgery. Histological type, differentiation grade, and TNM (tumor node metastasis) staging of all specimens was obtained from H\&E-stained slides 
Fig. 1. Scoring scheme for HER-2 and $\mathrm{p} 53$ staining. Positive control $(\times 100)(\mathbf{a}, \mathbf{b})$, negative staining at $\times 100(0)(\mathbf{c}, \mathbf{d})$ and strong positive, complete membranous staining at $\times 100(+2)(\mathbf{e}, \mathbf{f})$.
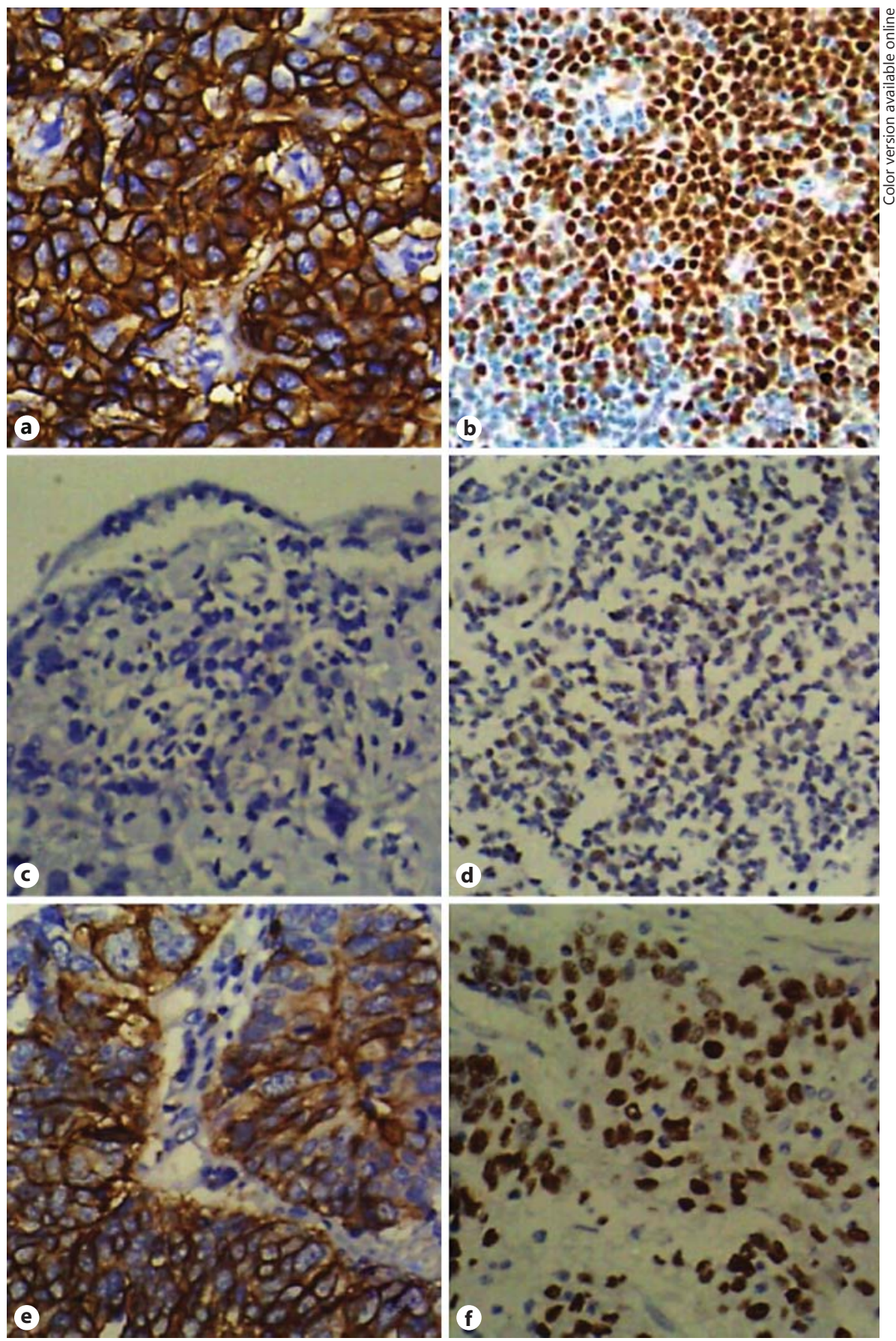

and hospital records. Patients' follow-up statuses were obtained either at a follow-up visit or through contact with the patients or their relatives. Clinicopathological features of all patients are summarized in table 1 .

\section{Immunohistochemistry}

Formalin-fixed (10\%), paraffin-embedded GBC and control specimens were sectioned (3-5 $\mu \mathrm{m}$ thick) and placed on polylysine slides. The acquired sections were initially dewaxed using xylene and rehydrated in alcohol followed by immersion in $1.5 \% \mathrm{H}_{2} \mathrm{O}_{2}$ in methanol for about $10 \mathrm{~min}$. Washing was done with tap water to eliminate excess peroxide and the slide with normal rabbit sera was incubated for $10 \mathrm{~min}$ to block nonspecific binding. Residual serum was removed and the sections were rapidly treated with ready-touse primary antibodies and incubated for $30 \mathrm{~min}$ in a humid chamber. Monoclonal antibodies c-erbB-2 (anti-HER-2) and DO-7 (anti-p53) (Dako ${ }^{\circledR}$ Corporation, Carpinteria, Calif., USA) were used as the primary antibody. Prediluted $(1: 1,600)$ biotinylated second- 


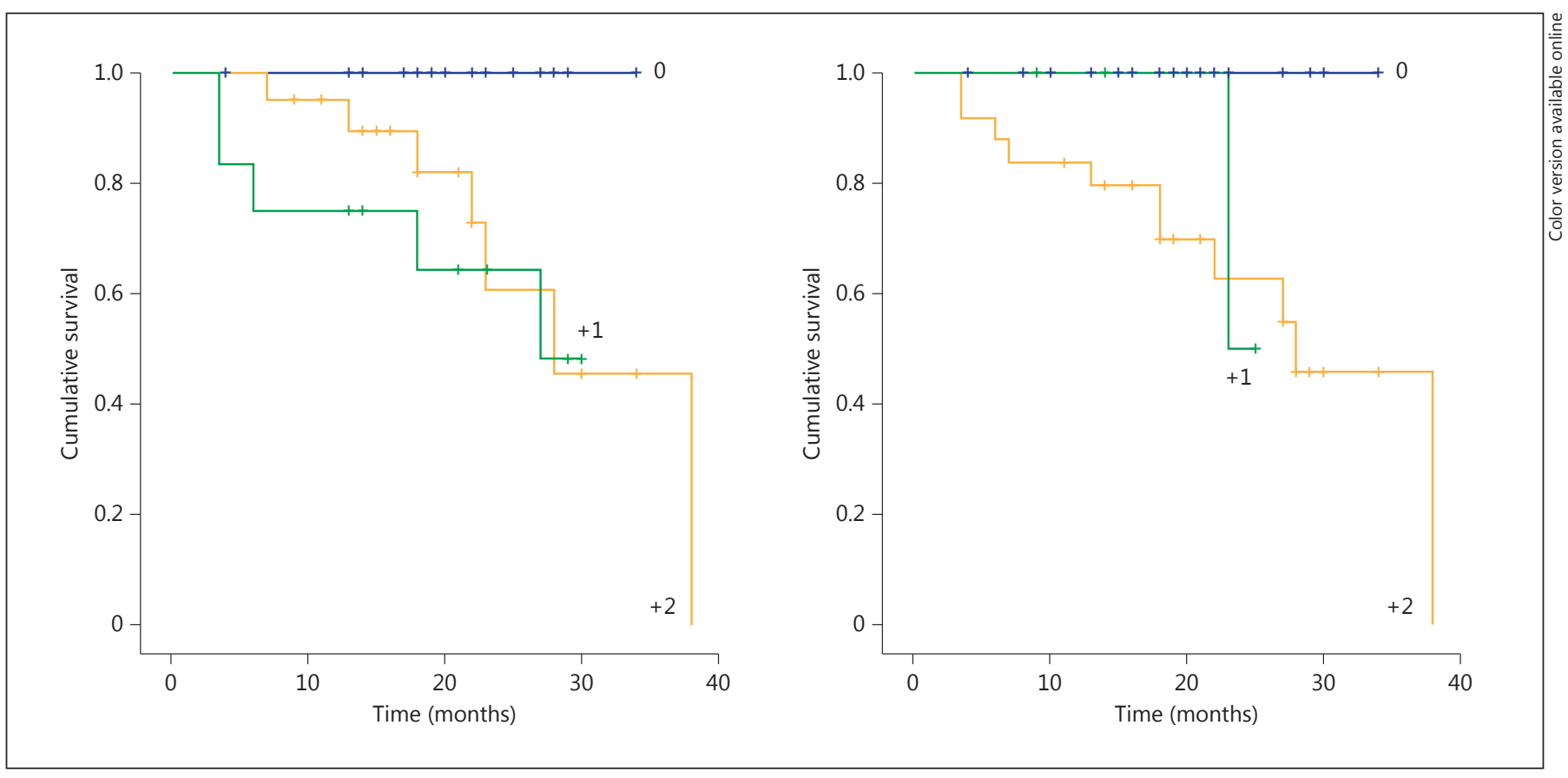

Fig. 2. Kaplan-Meier survival plots for HER-2 and p53 expression (control and tumor samples at different scores).

ary antibodies (horseradish peroxidase, Vector Laboratories Inc., Burlingame, Calif., USA) were applied to the sections for an hour after washing the slide with Tris buffer ( $\mathrm{pH}$ 7.6). The slides were repeatedly washed with Tris buffer saline for $10 \mathrm{~min}$ and finally the color was developed by the application of diaminobenzidine as the chromogen. Slides were then washed with tap water to arrest the biochemical processes followed by counterstaining with Harri's hematoxylin for a couple of minutes. The specimens were then washed, dried in alcohol and mounted with DPX.

\section{Scoring}

Scoring was based on the Herceptest ${ }^{\mathrm{TM}}$ (Dako) criteria; semiquantitative analysis of the stain intensity was carried out [14]. The number of HER-2-stained cells in 10 representative microscopic fields were counted and the percentage of positive cells was adjudged as negative ( 0 ) or barely perceptible staining in $<10 \%$ tumor cells ( 0$)$, weak staining in $<30 \%$ tumor cells $(+1)$, strong, complete membranous staining in $>30 \%$ cells $(+2)$ while p53 positivity was established when more than $50 \%$ tumor cells exhibited complete nuclear staining $(+3)$ [15].

\section{Statistics}

Statistical analysis was performed with two-sided $\chi^{2}$ test using SPSS software 23.0. Fisher's exact test was used for the analysis of contingency tables and evaluation of variance for the averages. $\mathrm{Cu}$ mulative survival rates and survival curves were calculated by Kaplan-Meier actuarial survival curves and log-rank tests. The Coxproportional hazards model was used to identify the hazard ratio (HR) and 95\% confidence interval (CI) of the clinical outcomes along with significant covariates for negative and positive patient groups. Statistical significance was set at $\mathrm{p}<0.05$.

Immunoexpression of HER-2 and p53 in GBC Patients

\section{Results}

The average age of the patient cohort was $52.34 \pm 10.84$ years, and $75 \%$ of them were females. $66.7 \%$ of cases reportedly had gallstones of variable sizes and the median tumor size was $30.68 \pm 22.55 \mathrm{~mm}$. All the cases were invariably histologically proven adenocarcinoma. Nearly $45 \%$ of the cases belonged to T-stages I and II, $28.33 \%$ of the patients showed lymph node positivity $(\mathrm{N})$ and $23.33 \%$ had metastatic behavior. About $36.67 \%(22 / 60)$ of the patients showed complete membranous staining for HER-2 as against only 5\% (3/60) of control cases ( $\mathrm{p}<$ $0.05)$ and $33.3 \%(20 / 60)$ of the tumor cases showed positivity for $\mathrm{p} 53$ while $1.7 \%(1 / 60)$ of the control cases showed complete nuclear staining (fig. 1). Contingency table analysis by $\chi^{2}$ tests revealed that HER-2 positivity showed significance with sex $(p=0.02)$, T-stage $(p=0.03)$, nodal metastasis $\mathrm{N}(\mathrm{p}<0.001)$ and distant metastasis $\mathrm{M}(\mathrm{p}<$ 0.001). On the other hand, p53-positive cases did not show any significance with clinicopathological factors. Univariate analysis using Kaplan-Meier survival plots revealed that nodal metastasis $(\mathrm{p}<0.001)$, HER-2 expression $(\mathrm{p}<0.05)$ and $\mathrm{p} 53$ expression $(\mathrm{p}<0.05)$ showed statistical significance (fig. 2). Application of the Cox-proportional hazards model (multivariate analysis) indicated HER-2 ( $\mathrm{p}=0.04$; HR: 2.36; 95\% CI: 1.04-5.33) and p53 
Table 2. Univariate and multivariate analysis of survival (months) with GBC

\begin{tabular}{|c|c|c|c|c|}
\hline \multirow[t]{2}{*}{ Parameter } & \multicolumn{2}{|l|}{ Univariate } & \multicolumn{2}{|l|}{ Multivariate } \\
\hline & $95 \% \mathrm{CI}$ of mean & $\mathrm{p}$ value $\mathrm{a}^{\mathrm{a}}$ & HR of death (95\% CI) & $\mathrm{p}$ value $\mathrm{b}^{\mathrm{b}}$ \\
\hline Gender & & 0.38 & $2.50(0.30-20.65)$ & 0.35 \\
\hline Male & $27.26-39.74$ & & & \\
\hline Female & $23.64-31.42$ & & & \\
\hline Gallbladder stones & & 0.72 & $1.23(0.30-5.54)$ & 0.72 \\
\hline Present & $24.11-35.84$ & & & \\
\hline Absent & $24.39-33.69$ & & & \\
\hline Histology & & 0.88 & $1.13(0.45-2.85)$ & 0.79 \\
\hline G1 & $25.76-38.76$ & & & \\
\hline G2 & $22.25-33.99$ & & & \\
\hline G3 & $23.22-31.35$ & & & \\
\hline Lymph node $(\mathrm{N})$ & & 0.05 & $3.90(0.86-17.68)$ & 0.08 \\
\hline Present & $18.33-30.01$ & & & \\
\hline Absent & $30.12-38.24$ & & & \\
\hline Pathological grade $(\mathrm{T})$ & & 0.37 & $0.45(0.07-2.70)$ & 0.38 \\
\hline $\mathrm{I}+\mathrm{II}$ & $19.11-27.10$ & & & \\
\hline III+IV & $26.46-35.23$ & & & \\
\hline Distant metastasis (M) & & 0.99 & $0.99(0.12-8.31)$ & 0.99 \\
\hline Present & $29.00-29.00$ & & & \\
\hline Absent & $26.23-35.88$ & & & \\
\hline Lymphovascular invasion & & 0.87 & $0.87(0.16-4.83)$ & 0.87 \\
\hline Present & $27.52-29.48$ & & & \\
\hline Absent & $26.48-37.12$ & & & \\
\hline Perineural invasion & & 0.51 & $1.71(0.34-8.59)$ & 0.51 \\
\hline Present & $24.15-30.23$ & & & \\
\hline Absent & $25.74-34.13$ & & & \\
\hline HER-2 expression & & 0.05 & $2.83(1.16-6.88)$ & 0.04 \\
\hline 0 & - & & & \\
\hline+1 & & & & \\
\hline+2 & & & & \\
\hline p53 expression & & 0.02 & $51.82(0.13-20,340)$ & 0.03 \\
\hline Present & - & & & \\
\hline Absent & & & & \\
\hline
\end{tabular}

( $p=0.03$; HR: $5.63 ; 95 \%$ CI: 1.21-26.26) expression to be significant prognostic factors in the selected GBC cohort (table 2).

\section{Discussion}

GBC is a neoplasm pertinently prevalent in select parts of the world. The majority of investigations that have been reported vary greatly due to geographical and racial disparities. North India presents itself as a major hub for this deadly cancer with a varied gene and protein expression profile. The pathogenesis of GBC is a much talked about phenomenon and often reports the involvement of major proto-oncogenes such as EGFR, HER-2 and tumor suppressor genes such as p53 [16]. In this study, we therefore attempt to identify the immunoexpression of HER-2 and $\mathrm{p} 53$ receptor proteins in $60 \mathrm{GBC}$ patients. The primary reasons for skewed results obtained from the same as well as different regions can be attributed to the source of antibodies used for immunohistochemistry, race of the patient cohort, and criteria used to adjudge positivity in the stained samples [17].

A number of recent studies have identified ERBB signaling to be the most frequently mutated pathway [18] in GBC (36.8\%) giving rise to their oncogenic potential and underlines the significance of HER-2 in GBC development and progression. However, in a rather unusual 
study, Toledo at al. [19] reported the overexpression of HER-2 as an early event in intestinal metaplasia (92\%), carcinoma in situ (90\%) and invasive GBC (33\%). In our preliminary investigation, the HER-2 expression profile showed relevance in higher-stage cases and significance with T-stage and nodal spread $(\mathrm{N})$ of the disease, which is often seen in advanced GBC cases. In a rather recent study conducted by Yoshida et al. [20], they found a significant patient population that can derive benefit from anti-HER-2 therapy by designing planned clinical trials based on preliminary immunohistochemical reports.

Several human cancers have reportedly shown the involvement of the PI3K/Akt/mTOR pathway in the pathogenesis with remarkable effects on cell cycle progression, cell proliferation, and angiogenesis. Deregulation of PI3K signaling as a consequence of PIK3CA mutations or PTEN loss has been described in 5-12 and $50 \%$ of human GBC, respectively [13]. Tian et al. [21] investigated the involvement of the p53 gene in regulating tumor angiogenesis and correlated it with tumor progression and increased vascularity. However, Chaube et al. [22] in their study regarded it to be involved in early phases of GBC while the majority of other studies considered it to be otherwise. Shu et al. [23] conducted an immunohistochemical study of benign and malignant lesions of GBC and also suggested the prognostic role of $\mathrm{p} 53$. We found that $\mathrm{p} 53$ expression was observed in almost one third of the selected patient cohort and presented itself along with HER-2 as an independent prognostic factor indicating worse prognosis. In the past, the treatment for all sorts of biliary tract cancers used to be identical. However, improvements in nextgeneration sequencing and other molecular techniques, and differentiation between these tumor types have confirmed that each tumor type (GBC, intrahepatic cholangiocarcinoma, and extrahepatic cholangiocarcinoma) has a unique molecular signature. It is therefore important for identifying drugs targeting specific pathways that can be utilized in biomarker-driven clinical trial designs. Therefore, preliminary studies from endemic regions for GBC such as India are critical to define prospective patient subsets that may derive benefit from targeted therapy.

Consequently, it can be summed up that there is an imperative necessity to search for archetype markers of GBC, which will not only diagnose and prognosticate the disease but also help in choosing the apposite modality of therapy, which may give us an opportunity to make headway in our basic understanding of GBC biology and man- agement paradigms. Furthermore, an accurate molecular characterization of tumors is necessary for the enrolment of patients in clinical trials in order to define which patient groups are likely to gain the most from targeted therapy. Multiple cellular pathways influence the growth and metastatic potential of tumors creating heterogeneity, termination, and the potential for tumors to overcome the signaling pathway blockade, resulting in primary or acquired resistance. Combining therapies that inhibit different intracellular signaling pathways have the potential to be more effective than inhibition of a single pathway and overcoming tumor resistance. A new promise in gallbladder treatment is the inhibition of the master heat shock protein 90 , a protein that in the last decade has emerged as an exciting target for cancer therapy, which is a master regulator of the stability and activity of multiple oncoproteins such as p53, HER-2, Akt, Bcr-Abl, c-Kit, EGFR and mutant BRAF [24]. Thus, our study assesses the expression of two major genes involved in the pathogenesis of GBC, correlates it with clinicopathological parameters and establishes it as an independent prognostic factor in GBC.

\section{Acknowledgement}

The authors are thankful to the Department of Science and Technology (DST) for providing financial support for conducting this study in the form of DST-INSPIRE fellowship.

\section{Disclosure Statement}

The authors declare no conflict of interest.

$\begin{aligned} \text { References } & \text { Clegg LX, Li FP, Hankey BF, Chu K, Edwards } \\ & \text { BK: Cancer survival among US whites and } \\ & \text { minorities: a SEER (Surveillance, Epidemiol- } \\ & \text { ogy, and End Results) program population- } \\ & \text { based study. Arch Intern Med 2002;162: } \\ & 1985-1993 . \\ 2 & \text { Hundal R, Shaffer EA: Gallbladder cancer: } \\ & \text { epidemiology and outcome. Clin Epidemiol } \\ & 2014 ; 6: 99-109 . \\ 3 & \text { Nandakumar A, Gupta PC, Gangadharan P, } \\ & \text { Visweswara RN, Parkin DM: Geographic pa- } \\ & \text { thology revisited: development of an atlas of } \\ & \text { cancer in India. Int J Cancer 2005;116:740- } \\ & 754 . \\ 4 & \text { Murthy NS, Rajaram D, Gautham MS, et al: } \\ & \text { Trends in incidence of gallbladder cancer - } \\ & \text { Indian scenario. Gastrointest Cancer Targets } \\ & \text { Ther 2011;1:1-9. }\end{aligned}$


5 Henley SJ, Weir HK, Jim MA, Watson M, Richardson LC: Gallbladder cancer incidence and mortality, United States 1999-2011. Cancer Epidemiol Biomarkers Prev 2015;24: 1319-1326.

-6 Gourgiotis S, Kocher HM, Solaini L, Yarollahi A, Tsiambas E, Salemis NS: Gallbladder cancer. Am J Surg 2008;196:252-264.

-7 Sicklick JK, Fanta PT, Shimabukuro K, Kurzrock R: Genomics of gallbladder cancer: the case for biomarker-driven clinical trial design. Cancer Metastasis Rev 2016;1-13.

8 Andrén-Sandberg Å: Molecular biology of gallbladder cancer: potential clinical implications. N Am J Med Sci 2012;4:435-441.

-9 Kumari N, Corless C, Warrick A, Beadling C, Nelson D, Neff T, et al: Mutation profiling in gallbladder cancer in Indian population. Indian J Pathol Microbiol 2014;57:9.

10 Maurya SK, Tewari M, Mishra RR, Shukla HS: Genetic aberrations in gallbladder cancer. Surg Oncol 2012;21:37-43.

-11 Omar N, Yan B, Salto-Tellez M: HER2: an emerging biomarker in non-breast and nongastric cancers. Pathogenesis 2015;2:1-9.

-12 Yan M, Schwaederle M, Arguello D, Millis SZ, Gatalica Z, Kurzrock R: HER2 expression status in diverse cancers: review of results from 37,992 patients. Cancer Metastasis Rev 2015; 34:157-164.
13 Rosner M, Hanneder M, Siegel N, Valli A, Fuchs C, Hengstschläger M: The mTOR pathway and its role in human genetic diseases. Mutat Res Mutat Res 2008;659:284-292.

14 Jacobs TW, Gown AM, Yaziji H, Barnes MJ, Schnitt SJ: Specificity of HercepTest in determining HER-2/neu status of breast cancers using the United States Food and Drug Administration-approved scoring system. J Clin Oncol 1999;17:1983-1983.

15 Mehta A, Sinha R, Azam S, Batra U, Doval D: Expression of epidermal growth factor receptor, $\mathrm{p} 53, \mathrm{Bcl} 2$, vascular endothelial growth factor, cyclooxygenase-2, cyclin D1, human epidermal receptor-2 and Ki-67: association with clinicopathological profiles and outcomes in gallbladder carcinoma. J Carcinog $2014 ; 13: 10$

16 Sergeant G, Lerut E, Ectors N, Hendrickx T, Aerts R, Topal B: The prognostic relevance of tumor hypoxia markers in resected carcinoma of the gallbladder. Eur J Surg Oncol 2011; 37:80-86.

17 Shafizadeh N, Grenert JP, Sahai V, Kakar S: Epidermal growth factor receptor and HER$2 /$ neu status by immunohistochemistry and fluorescence in situ hybridization in adenocarcinomas of the biliary tree and gallbladder. Hum Pathol 2010;41:485-492.

18 Li M, Zhang Z, Li X, Ye J, Wu X, Tan Z, et al: Whole-exome and targeted gene sequencing of gallbladder carcinoma identifies recurrent mutations in the ErbB pathway. Nat Genet 2014;46:872-876.
9 Toledo C, Matus CE, Barraza X, Arroyo P, Ehrenfeld $\mathrm{P}$, Figueroa $\mathrm{CD}$, et al: Expression of HER2 and bradykinin $B_{1}$ receptors in precursor lesions of gallbladder carcinoma. World J Gastroenterol 2012;18:1208-1215.

20 Yoshida H, Shimada K, Kosuge T, Hiraoka N: A significant subgroup of resectable gallbladder cancer patients has an HER2 positive status. Virchows Arch 2016;468:431-439.

-21 Tian Y, Ding R-Y, Zhi Y-H, Guo R-X, Wu S-D: Analysis of p53 and vascular endothelial growth factor expression in human gallbladder carcinoma for the determination of tumor vascularity. World J Gastroenterol 2006;12: 415-419.

-22 Chaube A, Tewari M, Garbyal RS, Singh U, Shukla HS: Preliminary study of p53 and cerbB-2 expression in gallbladder cancer in Indian patients. BMC Cancer 2006;6:126.

23 Shu G, Lv F, Yang Z, Miao X: Immunohistochemical study of PUMA, c-Myb and p53 expression in the benign and malignant lesions of gallbladder and their clinicopathological significances. Int J Clin Oncol 2012;18:641650.

24 Shirota T, Ojima H, Hiraoka N, Shimada K, Rokutan H, Arai Y, et al: Heat Shock Protein 90 is a potential therapeutic target in cholangiocarcinoma. Mol Cancer Ther 2015;14: 1985-1993. 